\title{
El régimen jurídico del teletrabajo en las administraciones públicas
}

\author{
Miguel SÁNCHEZ MORÓN \\ Catedrático de Derecho Administrativo \\ Universidad de Alcalá
}

\begin{abstract}
RESUMEN
Una de las consecuencias de las medidas adoptadas para combatir la epidemia de covid-19 ha sido la difusión del teletrabajo, tanto en la empresa privada como en las administraciones públicas, debido a las restricciones de movilidad. Esta modalidad de desempeño de las funciones públicas no es, sin embargo, novedosa, ya que habia empezado a regularse en nuestro país desde hace una más de una década, pues está vinculada a la implantación de las tecnologías de la información y la comunicación en el ámbito público. Ahora y en virtud de una reforma legal de 2020, el Estatuto Básico del Empleado Público la regula en sus aspectos esenciales. Esta legislación básica es complementada por un conjunto de normas o de acuerdos con los sindicatos aprobados por las Comunidades Autónomas y otras administraciones públicas. En este trabajo se resume el régimen jurídico en vigor, teniendo en cuenta sobre todo los elementos comunes de toda esa normativa.
\end{abstract}

Palabras clave: teletrabajo; Administraciones públicas; covid-19.

\begin{abstract}
The spread of teleworking, both in private companies and in the public administration, is one of the consequences of the struggle against covid-19 pandemic. Howewer, teleworking is not really a new mode of public service performance. It was already a decade ago that it had begun to regulate it in Spain, since it is linked to the development of digital tecnologies in the public administrations. In 2020 a new article on teleworking has been added to the framework law for civil servants. This basic legislation is now specified by regional and local regulations and agreements. This paper presents a summary of the current legal regime on the matter.
\end{abstract}

Keywords: teleworking; public administrations; covid-19. 
SUMARIO: I. ANTECEDENTES, IMPORTANCIA Y PERSPECTIVAS DEL TELETRABAJO EN EL SECTOR PÚBLICO.-II. DEFINICIÓN, FINALIDADES Y NATURALEZA JURÍDICA DEL TELETRABAJO.-III. ÁMBITO DE APLICACIÓN.-IV. LA COMPATIBILIDAD CON EL TRABAJO PRESENCIAL.-V. LA AUTORIZACIÓN DE TELETRABAJO.-VI. CONDICIONES DE EJERCICIO DEL TELETRABAJO.-VII. DERECHOS Y DEBERES.-VIII. SEGUIMIENTO Y EVALUACIÓN.

\section{ANTECEDENTES, IMPORTANCIA Y PERSPECTIVAS DEL TELETRABAJO EN EL SECTOR PÚBLICO}

El confinamiento domiciliario de la mayor parte de la población bajo el estado de alarma decretado por la pandemia de covid-19 y las posteriores restricciones a la movilidad establecidas por la misma causa han impulsado de manera exponencial la práctica del teletrabajo o trabajo a distancia, tanto en el sector privado como en el ámbito de las administraciones y demás entidades del sector público. Con independencia de este motivo coyuntural, lo cierto es que durante los últimos meses se han difundido unos hábitos de trabajo hasta entonces muy poco desarrollados en nuestro suelo. Y, con toda probabilidad, esos hábitos permanecerán una vez superada la situación de emergencia sanitaria, en mayor o menor medida.

El legislador estatal ha sentido, quizá por ello, la necesidad de abordar este fenómeno no solo de manera provisional, sino permanente. Por lo que se refiere al empleo público, que es lo que aquí interesa, lo ha hecho mediante el Real Decreto 29/2020, de 29 de septiembre, que añade un art. 47 bis al Texto Refundido del Estatuto Básico del Empleado Público, cuyo contenido fue acordado en la Mesa General de Negociación de las Administraciones Públicas, previo impulso de la Conferencia Sectorial de Administración Publica. A partir de ahí e incluso en fechas algo anteriores se han aprobado una buen número de reglamentaciones o acuerdos para el desarrollo del teletrabajo en muy distintas administraciones públicas o para ámbitos sectoriales de las mismas; regulaciones estas que coinciden en lo esencial, aunque difieren en muchos aspectos de detalle.

No estamos, sin embargo, ante una modalidad de desempeño de las funciones públicas totalmente nuevo. En realidad, desde siempre ha habido algunos grupos de funcionarios públicos habituados a compaginar el trabajo en la sede oficial de su puesto de trabajo con la realización de una parte de sus tareas en sus domicilios o lugares de trabajo privados, especialmente tratándose de actividades de estudio o de redacción de informes, propuestas, proyectos y otros escritos. Es el caso de muchos docentes universitarios, de bastantes miembros de la magistratura y de otros funcionarios de nivel superior. Pero eran supuestos excepcionales. La difusión del trabajo a distancia entre el conjunto de los empleados públicos está, en cambio, relacionada con la implantación progresiva de las tecnologías de la información y las comunicaciones, que facilitan el acceso a múltiples datos, publicaciones y documentos por la vía telemática, así como la conexión entre los 
propios empleados, sus superiores y sus subordinados, y en ocasiones con los usuarios o destinatarios de los servicios, sea por correo electrónico, sea por audio o videoconferencia. A medida que ha avanzado la digitalización de las administraciones públicas, la posibilidad y el interés en trabajar a distancia se ha venido incrementando.

Como suele suceder en el marco de la burocracia pública, toda nueva situación aboca a una nueva regulación. Así, desde hace más de una década algunas administraciones empezaron a aprobar normas sobre el teletrabajo de sus empleados. Primero como experiencias piloto; por ejemplo, la Administración General del Estado lo hizo mediante Orden APU/1981/2006, de 21 de junio. Más tarde y mucho antes de que nos sorprendiera la crisis sanitaria, algunos gobiernos o administraciones habían adoptado ya una normativa general al respecto o bien reglas sectoriales para algunos servicios o áreas del empleo público.

Por enumerar, sin pretensiones de exhaustividad, algunas de esas primeras reglamentaciones generales, mencionaremos el Decreto del Gobierno Vasco 92/2012, de 29 de mayo, que aprueba el Acuerdo con los sindicatos sobre teletrabajo en la Administración General de Euskadi y sus organismos autónomos; el Decreto 36/2013, de 28 de junio, del Consejo de Gobierno de las Islas Baleares; el Decreto 57/2013, de 12 de agosto, de la Junta de Comunidades de Castilla-La Mancha; el Decreto 45/2013, de 5 de diciembre, del Gobierno de La Rioja; la Orden de 20 de diciembre de 2013, de la Vicepresidencia y Consejerías de Administraciones Públicas y de Hacienda de la Xunta de Galicia; el Decreto 82/2016, de 8 de julio, del Consell de la Generalitat Valenciana; o el Decreto 16/2018, de 7 de junio, de la Junta de Castilla y León. Todas estas normas tienen un contenido similar y se aplican a los empleados de las respectivas administraciones generales autonómicas, con algunas señaladas excepciones. Por lo demás, la mayoría de sus reglas son coherentes y compatibles con lo que ahora se establece en la legislación básica del Estado, de manera que continúan en vigor, salvo las que han sido sustituidas por otras más recientes.

En cualquier caso, ha sido a partir del pasado año cuando este tipo de reglamentaciones o los correspondientes acuerdos de las mesas de negociación se han multiplicado. En ocasiones para regular la materia tan solo en el marco de la crisis de la covid-19, a la espera de una definitiva regulación para el futuro, como establece, por ejemplo, el Pacto de la Mesa General de la Administración de la Junta de Andalucía, suscrito el 14 de septiembre de 2020, que aprueba el Protocolo sobre el régimen del trabajo no presencial (publicado por Resolución de 16 de septiembre de 2020 de la Secretaría General para la Administración Pública). Pero en otros casos se trata de regulaciones por tiempo indefinido, entre las que sobresalen el Decreto 77/2020, de 4 de agosto, del Consejo de Gobierno de la Generalitat de Cataluña, el Decreto 79/2020, de 16 de septiembre, del Gobierno de la Comunidad de Madrid, o la Orden de 14 de diciembre de 2020 de la Consejería de Hacienda y Administración Pública de la Xunta de Galicia, que publica un nuevo Acuerdo sobre la materia, sustitutivo del ya mencionado de 2013. Además, en los boletines oficiales pueden encontrarse también los reglamentos o acuerdos apro- 
bados por numerosos ayuntamientos y entidades locales. A lo que habría que añadir las disposiciones, normas, instrucciones, protocolos o pactos de diverso tipo y alcance que regulan, al menos para este periodo de crisis, el trabajo no presencial en ámbitos determinados del empleo público, como la Administración de Justicia, las universidades o la enseñanza no universitaria, entre otros.

Como es natural, no podemos dar cuenta en este trabajo de toda esa normativa, tan extensa. Pero tampoco basta con analizar el nuevo art. 47 bis del Estatuto Básico del Empleado Público, ya que es muy escueto y está redactado en términos muy generales, como otros muchos preceptos del propio Estatuto. Su mera exposición e interpretación no bastaría para dar cuenta, ni cabal ni siquiera aproximada, de cómo está regulado el teletrabajo en nuestras administraciones públicas. Es más, no se trata de un precepto autoaplicativo, por así decir, ya que el mismo dispone que el teletrabajo se realizará en los términos de las normas que se dicten en su desarrollo, de manera que su aplicación efectiva depende de la aprobación de estas otras normas, más concretas. Por consiguiente, tomamos también en consideración el contenido de las normas generales en vigor aprobadas por las distintas Comunidades Autónomas para sus administraciones o servicios generales. Por fortuna, como se ha dicho, pero no por casualidad, dichas normas se asemejan bastante, lo que facilita nuestra tarea; dicho sea al margen de las diferencias de detalle, en las que no entraremos, salvo excepción.

\section{DEFINICIÓN, FINALIDADES Y NATURALEZA JURÍDICA DEL TELETRABAJO}

Conforme al art. 47 bis.1 del Texto Refundido del Estatuto Básico del Empleado Público, se considera teletrabajo «aquella modalidad de prestación de servicios a distancia en la que el contenido competencial del puesto de trabajo puede desarrollarse, siempre que las necesidades del servicio lo permitan, fuera de las dependencias de la Administración, mediante el uso de tecnologías de la información y la comunicación».

Teletrabajo no es, pues, en esta acepción legal cualquier trabajo «a distancia» o que se lleve a cabo fuera de las dependencias de la Administración, algo que, por otra parte, es consustancial a la realización de algunas tareas de servicio público (piénsese en las de vigilancia de la seguridad ciudadana, investigación de delitos o infracciones, actividades de protección civil, etc.), sino tan solo aquella prestación de servicios propia de un puesto de trabajo que se realiza en lugar ajeno a esas dependencias, pero mediante el uso de tecnologías de la información y la comunicación. Es, en definitiva, el tipo de trabajo que se puede realizar y normalmente se realiza (o se ha venido realizando habitualmente) en aquella dependencia pública que es la sede del puesto de trabajo, pero que pasa a realizarse a distancia en otro lugar, porque lo permite el uso de dichas tecnologías. Lo característico de esta modalidad es que, en virtud de ese uso, el trabajo del empleado público puede y viene a realizarse como si estuviera en la sede administrativa donde se ubica su puesto de trabajo. 
Por lo demás, no es necesariamente un trabajo que se ejecuta en el domicilio del empleado público. Esto puede ser lo más frecuente y lo que permite en la mayoría de los casos conciliar mejor la vida laboral y personal. Pero no es imprescindible. El teletrabajo puede realizarse en cualquier otro lugar, incluso alejado de la sede de la Administración para la que el empleado presta servicio o — por qué no- en el extranjero; o bien en lugares diferentes en cada momento, siempre que sean compatibles con los deberes y obligaciones del empleado que accede a esta modalidad. Hay que tener en cuenta al efecto, que en la mayoría de los casos el empleado que teletrabaja debe realizar una parte de sus funciones de manera presencial y que, en algunos casos, puede ser convocado de urgencia para ello. Por otra parte, como se dirá, el lugar de trabajo a distancia debe reunir algunas condiciones, tanto desde el punto de vista de la prevención de riesgos laborales como de la garantía de conexión a las redes informáticas, que permita llevarlo a cabo con seguridad y de manera efectiva y sin interrupciones. Pero, salvadas estas exigencias, no puede la Administración imponer al empleado un lugar determinado desde donde teletrabajar, salvo que así se contemple en la correspondiente autorización por causas justificadas. Más allá de eso prima la libertad del interesado para decidir desde dónde realizar ese trabajo a distancia.

La implantación del teletrabajo en las administraciones públicas responde, por otra parte, a determinados objetivos, que deben tenerse en cuenta al aplicar la regulación correspondiente. Ya hemos visto cómo, en casos de crisis, es una fórmula útil y a veces necesaria para solventar los problemas o restricciones a la movilidad y los que puede causar la concentración de personas en las oficinas y demás dependencias de la Administración. Pero más allá de eso, pensando en periodos de normalidad, se trata de una modalidad de trabajo que implica o debe conllevar una mayor flexibilidad en el desempeño de las funciones públicas. Esa flexibilidad puede a su vez conllevar ventajas desde el punto de vista de la eficacia administrativa y los resultados del trabajo personal, a condición de que esté bien organizada y, en su caso, supervisada. En este sentido se vincula o al menos debería vincularse al modelo de prestación o dirección por objetivos. A esto último se refiere expresamente el art. 47 bis. 2 del Estatuto Básico cuando señala que el teletrabajo «deberá contribuir a una mejor organización del trabajo a través de la identificación de objetivos y la evaluación de su cumplimiento». Además, contribuye a implementar la digitalización en el funcionamiento de las administraciones públicas, con todas sus consecuencias positivas, lo que a su vez es una condición para la implantación del sistema de teletrabajo y su difusión ${ }^{1}$.

Por otra parte, el teletrabajo genera o puede generar ciertas externalidades favorables, en particular facilitar la conciliación de la vida laboral con la personal y familiar, sobre todo en el caso de personas con mayores cargas familiares o con dificultades especiales de movilidad, o bien que precisen de un ámbito reservado de protección,

1 Así, por ejemplo, la reciente Ley de Aragón 1/2021, de 11 de febrero, subordina la aplicación del régimen de teletrabajo a la "previa, suficiente y efectiva implantación de la tramitación electrónica de los procedimientos en el centro directivo en que el empleado público preste servicio». 
como las empleadas objeto de violencia de género. Asimismo una amplia difusión del teletrabajo reduce sensiblemente los desplazamientos por razones de trabajo, lo que puede repercutir positivamente en los niveles de contaminación y en la mejora del medio ambiente ${ }^{2}$.

Dicho lo cual, el teletrabajo es una modalidad que no se concibe ya como excepcional o extraordinaria ${ }^{3}$. Antes bien, lo previsible es que vaya ganando mayor aceptación. Pero el art. 47 bis del Estatuto Básico del Empleado Público se preocupa de precisar que el teletrabajo en las administraciones públicas tiene en todo caso carácter voluntario y que puede desarrollarse «siempre que las necesidades del servicio lo permitan». Conviene detenerse en estos matices, sobre todo porque desde algunas esferas, particularmente sindicales, se proclama que tiene la naturaleza jurídica de un derecho de los empleados públicos.

Lo cierto es que la legislación básica, así como las normas autonómicas anteriores o posteriores que la complementan, no reconocen un derecho individual o subjetivo del empleado público al teletrabajo. Por una parte, esta modalidad solo puede implantarse cuando las necesidades del servicio público lo permitan, condición esta que corresponde valorar y determinar a la Administración competente en cada caso. Incluso una vez implantada o regulada la misma en un determinado ámbito o área de la Administración o para determinados grupos de empleados o puestos de trabajo, la legislación vigente no atribuye sin más a cada empleado interesado el derecho a acceder al teletrabajo. Por el contrario, eso es algo que debe ser solicitado a la Administración y, como se dirá, debe ser autorizado por esta, en función no solo del cumplimiento de ciertos requisitos, sino también de las necesidades del servicio. En fin, para el caso de que el teletrabajo se haya establecido y se haya autorizado a un empleado, el art. 47 bis del Estatuto Básico prevé que tiene carácter reversible, a cuyo efecto deberán tenerse en cuenta también, como veremos, las necesidades del servicio.

No hay, por tanto, en la legislación vigente un derecho de los empleados públicos al teletrabajo. Ahora bien, como es natural, la Administración no puede rechazar sin más una solicitud individual de acceso al teletrabajo, allí donde esté permitido, sino que tendrá que resolver sobre esa solicitud de acuerdo con la normativa aplicable y, si se rechaza, de manera motivada, de conformidad con el art. 35.1.a) e i) de la Ley 39/2015, del Procedimiento Administrativo Común. Los empleados públicos tienen derecho a solicitar la modalidad de teletrabajo en los ámbitos en que esté establecida y a obtener una respuesta motivada y fundada en derecho a esa solicitud, pero no a que se autorice en todo caso su acceso al teletrabajo, ya que no se trata de una decisión reglada.

2 Algunos decretos autonómicos mencionan estos posibles beneficios y objetivos. En particular el Decreto 79/2020, de la Comunidad de Madrid, los expone de manera sistemática y minuciosa en su art. 4, quizá con cierto exceso de pedagogía, más propio de una exposición de motivos que de un precepto jurídico.

3 El Acuerdo de 14 de diciembre de 2020 publicado por la Xunta de Galicia lo define expresamente como una modalidad de trabajo «de carácter estructural» y esa misma intención se deduce implícitamente del art. 47 bis del EBEP. 
Lo que sí está claro es que, en términos generales, tampoco la Administración puede imponer a sus empleados la modalidad de teletrabajo, en todo o en parte, ya que esta tiene carácter voluntario. Tampoco puede obligar a un empleado a mantener ese régimen de prestación, ya que el teletrabajo es en todo caso reversible. Sin embargo, el propio art. 47 bis del Estatuto Básico añade que la voluntariedad se entiende «salvo en supuestos excepcionales debidamente justificados». Sin duda se ha tenido en cuenta para incluir este inciso la actual situación de crisis sanitaria, que obliga a reducir drásticamente la movilidad y justifica la imposición de fórmulas de teletrabajo, tal como ha sucedido desde marzo de 2020 y sigue sucediendo a día de hoy. Pero pueden darse en el futuro otras circunstancias que también lo justifiquen, como por ejemplo, nuevas restricciones a la movilidad general debido a un alto índice de contaminación o a una catástrofe natural, o bien la realización de obras que inhabiliten temporalmente una sede administrativa o impidan el acceso a ella, etcétera ${ }^{4}$.

En suma, hay casos en que el teletrabajo puede ser una modalidad obligatoria. Pero por lo común es una forma de organización de la actividad administrativa que la Administración tiene la potestad de implantar y de regular de acuerdo con las necesidades de los servicios públicos, aunque no se puede imponer personalmente a cada empleado, sino autorizarla tan solo a quienes lo soliciten.

\section{III. ÁMBITO DE APLICACIÓN}

Como ya se ha dicho, la normativa sobre teletrabajo se va multiplicando y afecta cada vez a más administraciones y áreas de los servicios públicos. Pero es obvio que no todas las funciones o actividades públicas se pueden ejercer a distancia ni todos los empleados públicos pueden acogerse a esa forma de trabajo. Hay por ello una serie de límites y excepciones, tanto subjetivas como objetivas.

Dichos límites y excepciones no se contemplan en el Estatuto Básico del Empleado Público. Su art. 47 bis. 5 precisa tan solo que la regulación que contiene ese artículo se aplica también al personal laboral al servicio de las administraciones públicas, que se regirá en la materia no solo por el Estatuto sino también por sus normas de desarrollo. En consecuencia, el ámbito de aplicación de ese art. 47 bis es el del propio Estatuto Básico, que se establece en su art. 2, el cual por cierto no incluye el personal de las entidades del sector público estatal autonómico y local con personalidad jurídica de derecho privado, tales como sociedades mercantiles o fundaciones, que han de aplicar la legislación laboral al respecto. Las reglamentaciones autonómicas en vigor no diferencian tampoco entre personal funcionario y laboral a efectos de su aplicación.

Pero hay algunos límites que sí se encuentran en la legislación de desarrollo, que ya sabemos que es extensa y variada. Si nos atenemos a la legislación autonómica general

4 Vid., por ejemplo, el art. 14 del Decreto 79/2020 de la Comunidad de Madrid, que enumera las situaciones excepcionales o extraordinarias en que cabe exigir el teletrabajo y establece los requisitos para declararlo. 
que antes hemos mencionado, puede verse que no se aplica, por lo común, a grupos de empleados públicos tales como los docentes, personal sanitario, el de los cuerpos de policía y de protección civil, personal de las instituciones penitenciarias y, según algunas de esas normas, tampoco a otros colectivos como los agentes rurales, ciertos cuerpos de inspección, personal de las instituciones de justicia de menores o de actividades asistenciales o de servicios sociales. Pero esto no significa que ningún empleado de estos grupos pueda acceder al teletrabajo. En algunos casos la realización de sus funciones requiere la presencialidad, por su propia naturaleza, o al menos es altamente conveniente. No obstante lo cual, pueden existir reglas especiales para algunos servicios, tal como sucede hoy en día, durante la crisis epidémica, en el caso del personal docente universitario y no universitario, que se ve obligado a realizar en parte sus tareas de manera virtual.

En cualquier caso, ni siquiera en el ámbito de los servicios generales o de la Administración General, a que se refieren exclusiva o preferentemente las mencionadas normas autonómicas, todos los puestos de trabajo son susceptibles de desempeño mediante formas de teletrabajo. Con unos u otros matices todas esas normas coinciden en excluir la posibilidad de ejercicio a distancia de los puestos de trabajo que requieren de una atención directa al público de manera continuada, incluidos los de las oficinas de registro, más los puestos de dirección, coordinación y supervisión de equipos y las secretarías de cargos superiores y directivos ${ }^{5}$. Algunas normas extienden la excepción, de manera más genérica, a los puestos que precisen del acceso o del uso frecuente de información no automatizada ${ }^{6}$. Y cierta legislación opta, en sentido contrario, por enunciar el tipo de tareas y funciones que pueden desempeñarse de manera no presencial ${ }^{7}$, o por indicar las que preferentemente o de manera orientativa son susceptibles de esta modalidad de trabajo $^{8}$.

Hay que tener en cuenta, por lo demás, que a un determinado puesto de trabajo pueden corresponder una pluralidad de funciones, algunas susceptibles de desempeñar-

5 De manera más amplia, el Decreto 82/2016 de la Generalitat Valenciana excluye a todo el personal eventual y con nombramiento por libre designación (art. 4).

6 Así, el art. 7 del Decreto 79/2020 de la Comunidad de Madrid, que excluye: a) los puestos de trabajo que requieran un acceso frecuente de datos no informatizados; $b$ ) los puestos de trabajo que precisen el uso de información masiva no informatizada; $c$ ) los puestos de trabajo que generen información masiva en documentos no informatizados que necesiten ser archivados, sobre todo si deben ser consultados posteriormente por terceros; d) los puestos de trabajo que requieran un contacto directo frecuente con el público o con otras personas que resulte incompatible con la prestación de servicios en esta modalidad; $e$ ) los puestos de trabajo que no posibiliten que en el trabajo que el empleado desarrolle se puedan establecer objetivos de producción, en volumen de trabajo y en la calidad del mismo, y $f$ ) los puestos de trabajo cuyas funciones conlleven necesariamente la prestación de servicios presenciales en el lugar de trabajo, sin perjuicio de la capacidad organizativa del centro directivo correspondiente.

7 Así el art. 4 del Decreto 92/2012 del Gobierno Vasco, el art. 2.2 del Decreto 57/2013 de Castilla-La Mancha. o el Protocolo acordado por la Junta de Andalucía de 14 de septiembre de 2020. Entre las funciones o tareas a que se refieren estas normas están las de estudio y análisis de proyectos, elaboración de informes, propuestas o memorias, asesoría jurídica y técnica, redacción de documentos, inspección, gestión, análisis, diseño y programación de sistemas de la información y las comunicaciones, traducción, etcétera.

${ }^{8}$ Por ejemplo, el art. 3.3 del Decreto 36/2013 del Gobierno balear. 
se a distancia y otras no. Ello no debería ser un obstáculo para permitir el teletrabajo, siempre que el tiempo que haya que dedicar a unas y otras tareas pueda separarse o diferenciarse por días o, al menos, por franjas horarias. En cualquier caso son aspectos que deben examinarse en cada caso por el órgano competente para autorizar esa modalidad de desempeño del puesto.

\section{LA COMPATIBILIDAD CON EL TRABAJO PRESENCIAL}

Esa última consideración nos lleva a plantear también la relación que, según las normas vigentes, ha de existir entre trabajo presencial y teletrabajo. El art. 47 bis del Estatuto Básico se limita a indicar, de manera muy genérica, que el teletrabajo «será compatible con la modalidad presencial». Esto puede significar varias cosas, para lo que es necesario examinar también la legislación de desarrollo.

Ya se ha dicho que no cabe contemplar hoy el teletrabajo como un supuesto de excepción y lo previsible es que tienda a difundirse más en el futuro. Pero la citada disposición legal parece advertir contra una generalización de esta modalidad. El teletrabajo, según ella, no puede ser una alternativa general, sino más bien un complemento del trabajo presencial. Todavía alguna norma o acuerdo sigue calificando expresamente este último como la forma "ordinaria» de prestación de los servicios ${ }^{9}$. Aunque en otras ya no se considera así, lo que la legislación básica quiere expresar es que las diferentes administraciones públicas deben siempre asegurar que una parte del trabajo se realiza en la sede de los órganos, centros de trabajo o puestos correspondientes. Ello es tanto más necesario en los casos en que se requiere la atención al público o la comunicación del público con los funcionarios o empleados de que se trate, ya que no todos los ciudadanos tienen la posibilidad de comunicarse por medios telemáticos. Pero no solo eso. También es importante que cada empleado se integre y se considere integrado en la organización, lo que normalmente supone un contacto personal y directo con los superiores, compañeros y subordinados, que no es igual si tiene lugar en presencia o a través de audio o videoconferencia.

Algunas normas reguladoras del teletrabajo se preocupan por ello de garantizar un porcentaje mínimo de empleados trabajando de manera presencial en todo momento. Por ejemplo, el art. 5.4 del Acuerdo aprobado por la Orden de la Xunta de Galicia de 14 de diciembre de 2020 establece que, como regla general, cada órgano o centro debe contar con una presencia diaria mínima del 40 por 100 de sus efectivos, a cuyo efecto deben de acordarse rotaciones para todo el personal que desee trabajar a distancia. Pero esta regla puede ser objeto de excepción en el caso de órganos con escasa dotación de personal, en los que lo que haya que asegurar es simplemente que las necesidades del servicio no se vean afectadas. Por su parte, el Decreto 82/2016 de la Generalitat Valen-

\footnotetext{
9 Por ejemplo, el mencionado Protocolo de la Junta de Andalucía (ap. Segundo.1).
} 
ciana exige que al menos se halle siempre trabajando de manera presencial el 20 por 100 de los efectivos, excepción hecha de las ausencias justificadas, y que al menos un día a la semana toda la plantilla coincida en las dependencias de su sede. Entendemos que establecer ese tipo de porcentajes mínimos de presencialidad es una medida demasiado rígida y quizá en muchos casos muy poco operativa. Lo esencial es que por las autoridades o gestores competentes se examine caso por caso y en cada momento el número y tipo de empleados que deben trabajar en la sede del órgano o centro para cubrir de manera efectiva esas necesidades de los servicios.

De otra parte, la compatibilidad con el trabajo presencial ha sido entendida por las normas de desarrollo que hemos examinado, anteriores y posteriores a la introducción del art. 47 bis del Estatuto Básico, como una condición aplicable de manera singular a cada empleado que opta por el teletrabajo o es susceptible de hacerlo. Por un lado, dicha legislación impone límites temporales a las autorizaciones personales de teletrabajo, ya sea de un año o varios, en su caso prorrogable, o un plazo menor como señala expresamente alguna de ellas ${ }^{10}$, para evitar el desarraigo del empleado público autorizado. Y, por otro, lo normal es que solo se permita trabajar a distancia un número máximo de días a la semana, entre dos y tres según la legislación aplicable, y nunca una semana completa. Claro está que estas son reglas para una situación de normalidad y no para casos como el presente, en los que circunstancias excepcionales pueden obligar o aconsejar permanecer alejados de las oficinas públicas durante semanas enteras.

También determinan algunas normas de desarrollo si es posible o no fraccionar una misma jornada de trabajo entre una parte presencial y otra a distancia. En la mayoría de los casos se deniega expresamente tal posibilidad ${ }^{11}$, pero en algún caso se admite de manera excepcional ${ }^{12}$.

En definitiva, la compatibilidad entre el trabajo presencial y el teletrabajo debe organizarse y establecerse en cada caso, sobre la idea de que, salvo excepción justificada, siempre debe haber una parte del personal trabajando in situ, en las oficinas o centros públicos, y de que todo empleado público debe realizar de manera presencial una parte de su trabajo, mayor o menor, asimismo salvo excepción justificada. Pero, dado lo genérica que es la legislación básica, tales exigencias pueden traducirse y aplicarse de muy distintas maneras.

10 Art. 8.1 del Decreto 92/2012 del Gobierno Vasco. Con el límite temporal de la autorización, muy estricto en esta norma y como regla de seis meses, se pretende evitar no solo el desarraigo, sino también, como se dice en ella expresamente, «un cambio de hábitos y rutinas de tal magnitud que la vuelta a la modalidad presencial pueda causar algún perjuicio a la persona empleada».

11 Así, en las citadas normativas de la Generalitat de Cataluña (art. 4.3), de la Xunta de Galicia (art. 5.8), de la Generalitat Valenciana (art. 7.4) y del Gobierno de las Islas Baleares (art. 9.1).

12 Art. 21.2 del Decreto 79/2020 de la Comunidad de Madrid, que como regla general prohíbe el fraccionamiento de la jornada, pero lo admite por excepción en atención a las peculiaridades de las funciones asignadas a ciertos puestos de trabajo o por necesidades especiales de conciliación, o bien en el caso de los empleados que se encuentren sujetos a la prestación de servicio algunas tardes de la semana. 


\section{LA AUTORIZACIÓN DE TELETRABAJO}

Puesto que el acceso al teletrabajo es voluntario, pero está sujeto a las necesidades del servicio, la legislación básica y la que concreta su régimen jurídico lo condicionan a la obtención de una autorización, que se otorga a solicitud de los interesados. La legislación de desarrollo regula además, con mayor o menor detalle, el régimen de tales autorizaciones: requisitos, procedimiento, competencia para resolver, términos y límites, duración, suspensión, modificación y causas de extinción, etcétera.

Alguna reglamentación ${ }^{13}$ prevé que la asignación de teletrabajo pueda acordarse también mediante un procedimiento iniciado de oficio, de manera que sea la Administración la que tome la iniciativa de organizar y distribuir esa modalidad de desempeño de las funciones públicas en cada órgano, centro o dependencia. Pero en tales casos, la decisión final requiere del consentimiento de cualquier empleado afectado, ya que de lo contrario sería incompatible con el carácter voluntario que tiene el régimen de teletrabajo, según la legislación básica. Recordemos, no obstante, que en supuestos excepcionales debidamente justificados cabe también imponerlo obligatoriamente.

Por lo que se refiere a la autorización, las normas que hoy complementan el Estatuto Básico suelen exigir expresamente que quienes la soliciten sean empleados que se encuentren en situación de servicio activo, aunque algunas de ellas también aceptan que lo hagan quienes se hallan en una situación distinta, con reserva de puesto de trabajo (p. ej., en servicios especiales o en algunos tipos de excedencia y suspensión de funciones). En todo caso, la asunción del teletrabajo supone y requiere volver al servicio activo $^{14}$, por lo que en realidad lo que se quiere decir es que se puede conceder a quienes regresen a dicha situación y, naturalmente, desde que regresen. Lo que ocurre es que la posibilidad de trabajar a distancia quizá anime a algunos funcionarios en servicios especiales o en excedencia con reserva de puesto a reincorporarse a su puesto de trabajo originario. Quizá sea esta la razón por la que se añade la posibilidad de que soliciten la autorización aun no estando en servicio activo.

Un segundo requisito habitual es que quienes soliciten el teletrabajo dispongan de los conocimientos suficientes para utilizar las tecnologías de la información y las comunicaciones, que les permitan atender de manera efectiva y eficaz sus funciones. Ahora bien, las diferentes normas aplicables introducen unas $\mathrm{u}$ otras especificaciones al efecto. Las hay que se limitan a requerir ese tipo de conocimientos informáticos, que lógicamente deberían ser contrastados o verificados en cada caso. Otras exigen además un periodo mínimo de servicio en el puesto de trabajo, de forma presencial, durante el que pueden evaluarse las competencias y habilidades del solicitante en el manejo de dichas tecnologías. Algunas normas imponen un periodo de formación previo en la materia y, en su caso, ordenan a la Administración la organización de las correspondientes activi-

13 El citado Decreto 79/2020 de la Comunidad de Madrid, art. 8.1.

${ }_{14}$ Así lo dispone expresamente, por ejemplo, el art. 5.1 del Decreto 82/2016 de la Generalitat Valenciana. 
dades formativas. En cualquier caso, es claro que no se puede conceder la autorización para teletrabajar a quien no tenga la capacidad profesional o técnica suficiente para utilizar las herramientas informáticas necesarias. Pero hoy en día eso es cada vez menos un problema.

Un tercer requisito es que el lugar desde donde va a realizarse el teletrabajo cuente con una conexión segura a las redes telemáticas. En ocasiones se precisa que esa conexión debe ser de banda ancha o que debe reunir determinadas características técnicas para garantizar la continuidad del servicio, sin interrupciones. La Administración competente puede exigir, sin duda, las especificaciones técnicas que considere necesarias. Cosa distinta es quién debe abonar el coste de operación de tales conexiones y, en su caso, el de instalación y mantenimiento. Pero esta última cuestión enlaza con el deber de la Administración de proporcionar a sus empleados los medios tecnológicos necesarios para desarrollar su actividad, del que hablaremos más adelante.

En fin, es igualmente usual que las normas aplicables precisen que el lugar desde donde se va a trabajar a distancia cumpla los requisitos de seguridad, salubridad e higiene impuestos por la legislación de prevención de riesgos laborales. Es una exigencia lógica, pero no siempre fácil de comprobar, pues en muchos casos dicho lugar será un domicilio personal o familiar, al que no se puede acceder sin consentimiento del interesado o autorización judicial. Las administraciones competentes deberían imponer en tal sentido, como algunas normas exigen, la presentación de una declaración responsable o un cuestionario con la comunicación de algunos datos del lugar, sin perjuicio de llevar a cabo, en caso de duda, las pruebas o inspecciones consentidas necesarias para otorgar o mantener la autorización de teletrabajo ${ }^{15}$.

Obviamente, solo pueden obtener permiso para esta modalidad de trabajo los empleados públicos a los que se aplican las normas de que se trate y que ejerzan funciones o tareas que, conforme a dichas normas, admitan ese tipo de prestación. Pero no todos los que reúnan este y los demás requisitos señalados tienen derecho a obtener la autorización, ya que, como se ha dicho, la Administración puede disponer también que algunos de los empleados del órgano o centro deben trabajar de manera presencial, por necesidades del servicio. En tales casos y sin perjuicio de la posibilidad de rotación, a la que ya vimos que alude alguna regulación autonómica, es necesario determinar quiénes pueden acceder al teletrabajo y quiénes no. Sobre el particular las normas aplicables suelen establecer criterios de preferencia, a veces minuciosamente definidos y, en ocasiones, ponderados en función de un baremo incluido en un artículo o un anexo a la regulación correspondiente, que suponemos fruto de negociación pormenorizada con los sindicatos. No es sorprendente, pues es esta una cuestión en la que conviene evitar cualquier atisbo de agravio comparativo.

15 De manera expresa, el art. 9 del Decreto 82/2016 de la Generalitat Valenciana prevé una posible inspección previa del domicilio, con carácter voluntario, para comprobar que se cumplen las condiciones señaladas por el empleado en el cuestionario sobre salud laboral que debe presentar. 
Entre los criterios de preferencia, los más comunes son los que privilegian a las personas con discapacidad o con ciertos problemas de salud, así como los que atienden a la conciliación de la vida laboral y familiar, que benefician especialmente a quienes tienen personas a su cargo u otras cargas familiares. Asimismo algunas normas declaran la preferencia de las solicitantes que han sido objeto de violencia de género, ya que el teletrabajo puede ser una modalidad que las protege mejor de los riesgos de agresión. Otros criterios de preferencia son los que tienen que ver con la distancia entre el domicilio del interesado y el centro de trabajo o la dificultad de acceso a este por cualquier otro motivo. En fin, suele contar también la edad de los solicitantes, la realización de estudios por los empleados mientras trabajan, o la antigüedad o grado de la carrera. No debería, en cambio, ser motivo de preferencia el carácter indefinido o fijo de la relación de empleo, frente a interinos o trabajadores temporales, ya que no es conforme a Derecho establecer diferencias de trato fundadas exclusivamente en la duración de la relación de servicio o de empleo ${ }^{16}$.

Las normas aplicables regulan el procedimiento de otorgamiento de la autorización, que suele incluir un informe del órgano, del centro directivo o del jefe de la unidad a la que pertenece el empleado solicitante acerca de si cumple los requisitos para acceder al teletrabajo y sobre las necesidades del servicio. En realidad, poco más hay que tramitar, por lo que sorprende en cierto modo que en algunas regulaciones autonómicas ${ }^{17}$ se fije un plazo de tres meses para resolver, que parece excesivo. Otras, con mayor acierto, lo reducen a $\operatorname{dos}^{18} \mathrm{e}$ incluso a un mes ${ }^{19}$.

Una cuestión que puede ser controvertida es si, en caso de transcurso del plazo para resolver sobre la autorización solicitada, esta se debe entender otorgada o rechazada por silencio. La normativa autonómica no ofrece una respuesta unívoca. Algunos reglamentos o acuerdos consideran que el silencio es negativo ${ }^{20}$ y otros que es positivo ${ }^{21}$, mientras que hay otras normas que no se pronuncian al respecto. El art. 47 bis.2 del Estatuto Básico del Empleado Público dispone que «la prestación del servicio mediante teletrabajo habrá de ser expresamente autorizada». En una interpretación literal del precepto habría que entender que, a falta de autorización «expresa», no se considera aceptada la solicitud correspondiente. No está claro, sin embargo, que esa sea la voluntad del legis-

16 Sobre el particular existe una reiterada jurisprudencia de los tribunales europeos y españoles. Me permito remitirme sobre ello a mi libro El régimen jurídico de los funcionarios interinos, Aranzadi, Navarra, 2020, en especial pp. 65 y ss.

17 Así, por ejemplo, el citado Decreto 77/2020 de la Generalitat de Cataluña (art. 5.3), o el Decreto 16/2018 de Castilla y León (art. 24).

18 Por ejemplo, el Decreto 79/2020 de la Comunidad de Madrid (art. 10.3) y el Decreto 36/2013 del Gobierno de las Islas Baleares (art. 6.3).

19 Decreto 92/2012 del Gobierno Vasco, que incluso reduce el plazo máximo a quince días en determinados supuestos (arts. 5.4 y 5.6 del Acuerdo incorporado como Anexo al mismo).

20 Por ejemplo, el Decreto 36/2013, de las Islas Baleares (art. 6.3), y el Decreto 16/2018 de Castilla y León (art. 24).

21 Así el Decreto 77/2020 de Cataluña (art. 5.3) o el Acuerdo publicado por Orden de 14 de diciembre de 2020 de la Xunta de Galicia (art. 8.2). 
lador y tampoco parece que existan en este caso particulares razones de interés general para exceptuar la regla general del silencio positivo. Sin embargo, no se trata de una autorización reglada, ya que está condicionada a las necesidades del servicio, aparte de al cumplimiento de un conjunto de requisitos. Quizá por esto la legislación básica impone el carácter expreso de la autorización, lo que implica que no son conformes a ella las normas autonómicas que contemplan el silencio positivo.

Como es natural y señalan algunas normas autonómicas, la resolución expresa sobre la solicitud debe ser motivada, por tratarse de una decisión discrecional, máxime si se deniega la autorización mediante acto desfavorable [art. 35.1.a) e i) de la Ley 39/2015 del Procedimiento Administrativo Común].

Por lo que se refiere a la duración o duración máxima de la autorización para el trabajo a distancia, la legislación básica no establece ningún límite y la normativa autonómica presenta una variedad de soluciones. Lógicamente la duración debería concretarse en cada autorización. Pero en algunas normas no se añade nada más o incluso se prevé que pueda otorgarse esa autorización por tiempo indefinido ${ }^{22}$, mientras que en otras se fijan plazos máximos de un año (el más común) u otros, normalmente prorrogables ${ }^{23}$. En algún caso se establece también un plazo mínimo del teletrabajo autorizado ${ }^{24}$. Esos plazos máximos no excluyen la posibilidad de solicitar más tarde una nueva autorización de teletrabajo, normalmente sin continuidad con la anterior. Pero a veces se establece la prohibición de otorgar nueva autorización durante un tiempo al empleado que renunció a otra anterior sin causa justificada o al que incumplió los compromisos u objetivos vinculados a una autorización previa.

En fin, las normas o acuerdos que complementan la regulación del Estatuto Básico en esta materia establecen previsiones sobre la modificación y suspensión de la autorización de trabajo a distancia y sobre su término o extinción. Como se viene diciendo, la modalidad del teletrabajo tiene carácter reversible, lo que significa que puede ser revocada por la Administración en cualquier momento, por razones justificadas de interés público o necesidades del servicio. Por estas mismas razones, es posible suspender provisionalmente la autorización otorgada o modificar alguna de sus condiciones, como por ejemplo el número de horas o los días de la semana en régimen de teletrabajo.

Algunas normas regulan con detalle las causas de revocación o extinción de la autorización. Entre ellas se incluyen la renuncia de interesado, que en algún caso le impide solicitar nueva autorización durante un tiempo, salvo si se funda en justificación ob-

22 Decreto 57/2013, de Castilla-La Mancha (art. 6.4).

23 Así, el Decreto 77/2020 de la Generalitat de Cataluña (art. 4.1), que prevé no obstante la posibilidad de autorizaciones excepcionales de mayor duración, o el Decreto 16/2018, de Castilla y León (art. 7). El Acuerdo aprobado por Decreto 92/2012 del Gobierno Vasco (art. 8) establece que, por regla general, las autorizaciones de teletrabajo se conceden por seis meses, y como mucho hasta un año, lo que se justifica por la conveniencia de evitar el desarraigo del funcionario o empleado público en su puesto de trabajo o unidad.

24 Decreto 36/2013 del Gobierno balear (art. 8.1). 
jetiva ${ }^{25}$, el mutuo acuerdo y, por supuesto, la finalización del plazo de la autorización concedida. Pero también se puede revocar la autorización por el incumplimiento sobrevenido de los requisitos para su otorgamiento (por ejemplo, pérdida o dificultades sobrevenidas de conexión o cambio de puesto de trabajo o de las funciones asignadas al empleado autorizado, desaparición de una discapacidad o de la necesidad de conciliar), o por el incumplimiento de los compromisos asumidos por este o de los objetivos o resultados fijados en su plan individual de trabajo (del que tratamos más adelante) o de alguna otra de las condiciones impuestas. En fin, siempre es posible revocarla igualmente por otras razones objetivas relacionadas con las necesidades del servicio, que corresponde valorar a la Administración competente.

La revocación, que implica el retorno al trabajo presencial, debe ser motivada por tratarse de un acto desfavorable, salvo cuando derive de la renuncia del propio interesado. Las diferentes normas aplicables determinan también cuando deben reincorporarse los interesados al trabajo presencial desde que se extingue la autorización de trabajo a distancia.

\section{CONDICIONES DE EJERCICIO DEL TELETRABAJO}

Aparte de los requisitos para obtener la autorización de teletrabajo, que ya hemos comentado, el ejercicio de esta modalidad de desempeño de las funciones públicas está sujeto a una serie de condiciones, que tienen por finalidad garantizar la eficacia en la prestación de los servicios. Son condiciones sustitutivas de la inmediación y el contacto regular o personal que posibilita el trabajo presencial, que permite la transmisión en el momento de las órdenes e instrucciones de servicio y la supervisión directa del cumplimiento de los horarios y la ejecución de las tareas. Como en la relación virtual que el teletrabajo implica esto no existe o es difícil de conseguir, han de imponerse esas condiciones alternativas.

Las más relevantes son las que tienen que ver con la determinación y control o evaluación de trabajo que se realiza a distancia. Ya se dijo que el teletrabajo está vinculado a los métodos de la tradicionalmente conocida como dirección por objetivos y así lo recuerda ahora el art. 47 bis del Estatuto Básico: «El teletrabajo deberá contribuir a una mejor organización del trabajo a través de la identificación de objetivos y la evaluación de su cumplimiento». Pero este precepto básico no dice más.

En la legislación complementaria la autorización del trabajo a distancia se condiciona a la aprobación de un plan personal o programa individual de trabajo o de un documento de compromisos, que recibe estas u otras denominaciones similares, en el que los responsables del servicio u órganos de dirección competentes deben precisar las tareas que ha de realizar cada empleado en un cierto lapso de tiempo, ya sea diario, semanal

25 Art. 13.3 del Decreto 79/2020 de la Comunidad de Madrid. 
u otro. Han de definirse así los tipos de tareas y su volumen o cuantía y los indicadores de calidad o resultados a alcanzar, los horarios de interconexión o de disponibilidad, las obligaciones de información a los superiores y las formas, criterios y medios de supervisión. La eficacia del teletrabajo depende de estos planes o compromisos y, por tanto, de cómo se elaboren o aprueben por los titulares o responsables de cada servicio o unidad. Por lo demás, se considera que esos instrumentos han de ser flexibles y actualizarse periódicamente para atender a las circunstancias cambiantes y para corregir las eventuales disfunciones. Estas son reglas más o menos comunes que pueden encontrarse en las citadas normas de desarrollo, más allá de las cuales los detalles sobre el contenido, formalidades de aprobación o periodos de aplicación y revisión de estos planes individuales varían en cada caso.

La concreción de los objetivos y resultados a través de esos instrumentos de dirección implica a su vez una exigencia de evaluación o supervisión. Normalmente se establece que la supervisión del trabajo realizado debe ser continua, a cargo del responsable de la unidad, y que periódicamente deben elaborarse informes o memorias de resultados. A tal efecto es también importante el uso de las herramientas informáticas disponibles. Las consecuencias de la evaluación pueden consistir en la modificación de los planes individuales o de las condiciones de la autorización de teletrabajo o, si procede, la revocación de esa autorización, ya sea debida a incumplimientos del empleado interesado o a otras causas objetivas.

En relación con esta forma de organización del servicio se plantea la cuestión de la jornada y los horarios de trabajo. Se suele recalcar al efecto que la modalidad del teletrabajo no modifica la jornada de los empleados públicos establecida para la actividad presencial. Hay igualdad de derechos y obligaciones al respecto y, por consiguiente, el acceso al teletrabajo no supone ni puede suponer una disminución ni una prolongación o aumento de la jornada legalmente establecida en cada Administración, ya sea la jornada general o una jornada especial o reducida, si procede aplicarla. Tampoco varía el calendario laboral. Ahora bien, como señala con claridad y con realismo el Acuerdo sobre teletrabajo aprobado por el Decreto 92/2012 del Gobierno Vasco, «el teletrabajo, por su naturaleza, no comporta de manera inherente una especial dedicación de horario ni de jornada, sino una flexibilidad en la jornada y en los horarios ordinarios». Precisamente esta es una de sus ventajas, ligada también a la conciliación de la vida laboral con la familiar. Lo que importa es lo que se haga y no tanto cuándo se haga, siempre, claro está, que se respeten las necesidades del servicio.

En consecuencia, lo que las normas reguladoras prevén es que puedan fijarse a cada empleado a distancia unos horarios o franjas horarias determinadas de conexión con su unidad o centro de trabajo o con sus superiores o directivos y, en su caso, un horario mínimo en el que ha de estar disponible para posibles comunicaciones, ya sea por correo electrónico, teléfono o medios audiovisuales. Esas franjas horarias deben incluirse dentro de la jornada de trabajo prevista por la legislación general aplicable, respetando las horas de descanso entre una y otra. Establecidas tales previsiones en el plan individual 
o por decisión del centro directivo o del responsable competente y tal como señala expresamente el art. 6.2 del Decreto 77/2020 de la Generalitat de Cataluña, «el resto de la jornada en régimen de teletrabajo admite una flexibilidad total».

Otras de las condiciones de ejercicio son las que se refieren al uso de los equipos e instalaciones informáticas necesarias para este tipo de prestación. Dispone al efecto el art. 47 bis. 4 del Estatuto Básico que «la Administración proporcionará y mantendrá a las personas que trabajen en esta modalidad, los medios tecnológicos necesarios para su actividad». Ahora bien, también la interpretación y aplicación de este precepto suscita algunos interrogantes, que resuelven de diferente manera, cuando los resuelven, las normas de desarrollo. En principio, puesto que la legislación básica no distingue, debería entenderse que el empleado tiene derecho a que la Administración le proporcione o le abone el coste de los ordenadores, programas informáticos y conexiones necesarias para prestar el servicio en régimen de teletrabajo. Eso debería incluir, cuando sea preciso, las herramientas ofimáticas, de trabajo remoto o de trabajo colaborativo y de ciberseguridad, que sean aplicables, y en su caso el sistema de firma electrónica, tal como concreta alguna normativa reciente ${ }^{26}$. Pero en algún caso se establece que es el propio empleado autorizado a teletrabajar el que corre con los gastos de conexión ${ }^{27}$.

Uno de los problemas que esa obligación de la Administración plantea es que, en algunos aspectos, supone una duplicidad de medios y, por tanto, un incremento del gasto, ya que los empleados concernidos también han de realizar parte de su actividad en la sede de su unidad, en la que normalmente tendrán a su disposición otros medios tecnológicos. Pero quizá el problema más importante es que los equipos utilizados para el teletrabajo, así como las conexiones informáticas y quizá otros medios pueden usarse también para fines o actividades privadas del interesado. Algunos de ellos pueden incluso preferir utilizar sus propios equipamientos privados para el trabajo, sin perjuicio de las conexiones, programas o herramientas ofimáticas que les proporcione la Administración.

El Acuerdo publicado por la Orden de la Xunta de Galicia de 14 de diciembre de 2020 dispone al efecto que los medios tecnológicos proporcionados por la Administración «no se podrán utilizar para finalidades diferentes de las derivadas de la prestación de servicios que motivan su entrega el personal teletrabajador». Pero esta obligación es muy difícil de controlar y de garantizar. Lo que sí está claro es que el empleado autorizado debe asumir la responsabilidad del correcto uso de esos medios, que debe custodiar, conservar en buen estado y tener siempre disponibles para la finalidad con la que se entregaron, como precisa la citada Orden gallega ${ }^{28}$. Al fin y al cabo, ello no es sino una manifestación del deber de los empleados públicos, previsto en el art. 54.5 del Estatuto Básico, de no utilizar los bienes públicos en provecho propio o de personas allegadas y de velar por su conservación. Sobre ello tratamos también a continuación.

26 Por ejemplo, art. 16.2 del Decreto 79/2020 de la Comunidad de Madrid y el Acuerdo publicado por la Orden de la Xunta de Galicia de 14 de diciembre de 2020.

27 Art. 8.2 del Decreto 77/2020 de la Generalitat de Cataluña.

28 En el mismo sentido, art. 16.3 del Decreto 2020 de la Comunidad de Madrid. 


\section{DERECHOS Y DEBERES}

«El personal que preste sus servicios mediante teletrabajo tendrá los mismos deberes y derechos, individuales y colectivos, recogidos en el presente Estatuto que el resto del personal que preste sus servicios en modalidad presencial, incluyendo la normativa de prevención de riesgos laborales que resulte aplicable, salvo aquellos que sean inherentes a la realización de la prestación del servicio de manera presencial». Así reza el art. 47 bis.3 del Estatuto Básico del Empleado Público.

En realidad, no es fácil deducir diferencias en cuanto a los derechos aplicables en función de la naturaleza presencial o a distancia de la prestación del servicio. Ya se ha dicho que hay incluso una equivalencia en la extensión de la jornada laboral y, por supuesto, en materia de permisos y licencias, incluidos los tiempos de ausencia durante la jornada por lactancia u otras causas legales. Si acaso habrá algunas diferencias en cuanto a la forma o condiciones concretas de ejercicio de esos derechos, como ya hemos visto.

Hay que destacar, no obstante, la importancia que en caso de teletrabajo tienen los derechos relacionados con el uso de las tecnologías de la información y la comunicación y con la protección de datos personales. En tal sentido es muy significativa la introducción del apartado 14.j) bis del Estatuto Básico por la Ley Orgánica 3/2018, de 5 de diciembre, de protección de datos personales y garantía de los derechos digitales, que reconoce el derecho «a la intimidad en el uso de los dispositivos digitales puestos a su disposición [del empleado público] y frente al uso de dispositivos de vigilancia y geolocalización, así como a la desconexión digital» en los términos establecidos en esa legislación especial.

El derecho a la protección de la intimidad es aquí muy importante, pues el teletrabajo se presta desde el domicilio u otros espacios privados y porque, como se ha dicho, el empleado público puede utilizar en la práctica los medios tecnológicos con los que presta el servicio también para comunicaciones o conexiones personales. La Administración debe respetar la intimidad en el uso de esos dispositivos, incluso los que ella misma ha puesto a disposición del empleado público. No se trata, empero, de un derecho ilimitado, ya que, como se ha señalado antes, el empleado que teletrabaja debe hacer un uso adecuado de esos medios. El art. 87 de la mencionada Ley Orgánica 3/2018 permite al «empleador», es decir, a la Administración en nuestro caso, acceder a los contenidos derivados del uso de esos dispositivos digitales, solo para controlar el cumplimiento de las obligaciones estatutarias o de servicio y para garantizar la integridad de esos dispositivos. Sobre este tipo de cuestiones existe ya, por cierto, alguna jurisprudencia de interés y matizada, en la que no podemos entrar aquí, pues no solo se aplica en los supuestos de teletrabajo ${ }^{29}$.

29 Vid., por ejemplo, la Sentencia del Tribunal Europeo de Derechos Humanos de 22 de febrero de 2018, caso Libert contra Francia, sobre el acceso no consentido y en ausencia del interesado por parte de una «autoridad pública», como se califica a tales efectos a los responsables de la empresa pública SNCF, al disco duro del 
Por lo que se refiere al derecho del empleado público a la desconexión digital, fuera del tiempo o jornada de trabajo, que también garantiza y regula la Ley Orgánica 3/2018 (art. 88), es en este caso esencial. La flexibilidad horaria que el teletrabajo conlleva o puede conllevar no significa conexión continua o ilimitada con la Administración, pues deben garantizarse los derechos al descanso, a permisos y vacaciones y a la conciliación. La propia Ley Orgánica 3/2018 (art. 88.3) dispone que ese derecho a la desconexión digital debe preservarse en particular en los supuestos de trabajo a distancia o en el domicilio del empleado vinculado al uso con fines laborales de herramientas tecnológicas. Como se ha visto, alguna normativa aborda este aspecto imponiendo un horario de conexión o de disponibilidad al empleado, dentro de los márgenes de la jornada laboral. Y eso es lo correcto. Además, la citada Ley Orgánica establece que el empleador —en nuestro caso la Administración - ha de elaborar una política interna, previamente negociada, para definir las modalidades de ejercicio del derecho a la desconexión y las acciones de formación y sensibilización del personal sobre un uso razonable de las herramientas tecnológicas, que evite el riesgo de fatiga informática.

Por lo que se refiere a los deberes y obligaciones del empleado público, la modalidad a distancia no entraña tampoco demasiadas peculiaridades, más allá de la flexibilidad horaria que hemos comentado y de algunos deberes de formación específicos, en su caso. No obstante hay que poner el énfasis en algunos aspectos, como la necesidad de aplicar también en este caso la legislación sobre salud laboral y prevención de riesgos, tal como menciona el art. 47 bis.3 del Estatuto Básico. Hay que recordar que la observancia de las normas sobre seguridad y salud laboral no es solo un derecho del empleado público, sino también un deber (art. 54.9 del Estatuto Básico), ya que puede afectar a la buena marcha de los servicios. En el caso del teletrabajo, el empleado debe realizar su actividad en algún lugar o espacio que asegure el cumplimiento de aquellas normas. Es su responsabilidad, ya que se tratará de espacios privados, que la Administración no controla. Por eso alguna normativa de desarrollo exige a quienes soliciten la autorización de teletrabajo proporcionar información previa a la Administración, con el fin de que las unidades de prevención verifiquen las condiciones del lugar y características del teletrabajo y puedan formular las instrucciones y recomendaciones pertinentes ${ }^{30}$. Y en algún otro caso se exige incluso cursar una sesión formativa sobre el particular ${ }^{31}$.

Igualmente tiene especial relevancia la obligación de secreto, confidencialidad de las informaciones a las que el empleado acceda en el ejercicio de sus funciones y protección de datos personales de terceros. No se trata de obligaciones distintas de las que se imponen a quienes trabajan en la sede de la Administración, pero el trabajo a distancia,

ordenador profesional de un empleado, ante la sospecha de que, contra el código de conducta de la empresa, había hecho un uso habitual y no solo ocasional o esporádico del ordenador proporcionado por ella para fines privados. El Tribunal Europeo entendió que en este caso no se vulneró el derecho a la vida personal o a la intimidad del reclamante (art. 8 del Convenio Europeo).

30 Art. 17 del Decreto 79/2020 de la Comunidad de Madrid y art. 20 del Decreto 16/2018 de Castilla y León, por ejemplo.

31 Art. 20 del Decreto 92/2012 del Gobierno Vasco. 
menos controlado a priori, y el posible uso de las herramientas informáticas con que se lleva a cabo también para fines privados impone una especial cautela al efecto. En consecuencia, algunas normas prevén que se impartan instrucciones o una información detallada al empleado autorizado sobre sus obligaciones al respecto, incluidas las relativas a la seguridad informática, e incluso que se le exija un compromiso de cumplimiento ${ }^{32}$.

Asimismo el teletrabajo no supone de por sí ninguna modificación en el régimen jurídico de las incompatibilidades del personal al servicio de las administraciones públicas. Algunas normas reglamentarias precisan en tal sentido que la duración de la jornada de quienes acceden a esa modalidad es la misma que tendrían si desempeñaran sus tareas de manera presencial. Puede que en la práctica la flexibilidad horaria que conlleva el teletrabajo en muchos casos facilite a quienes se acogen a él la dedicación parcial o complementaria a actividades privadas. Pero eso no les exime del cumplimiento de sus funciones ni de la legislación de incompatibilidades, por lo que deberán solicitar en su caso el reconocimiento de compatibilidad con las actividades privadas de que se trate (art. 14 de la Ley 53/1984, de 26 de diciembre, de Incompatibilidades), asumiendo la consiguiente responsabilidad disciplinaria de no hacerlo así.

En fin, la modalidad de teletrabajo no implica tampoco modificaciones en el régimen disciplinario de los empleados públicos. Lo que sucede es que el incumplimiento de los deberes del servicio en estos casos, que podría ser constitutivo de falta, supone al mismo tiempo una causa de revocación de la autorización de trabajo a distancia, como ya se ha señalado.

\section{SEGUIMIENTO Y EVALUACIÓN}

No obstante la amplia experiencia derivada de las medidas contra la covid-19, aparte otras anteriores, el teletrabajo es aún una modalidad en vías de consolidación. Por eso en prácticamente todas las normas autonómicas que se han examinado se ordena la creación de comisiones de evaluación o de seguimiento, con distintas denominaciones y diferente composición, para analizar los resultados de la implantación de aquella, detectar problemas y eventuales deficiencias y estudiar soluciones. Estas previsiones suelen poner fin a las reglamentaciones o acuerdos con los sindicatos sobre la materia ${ }^{33}$.

32 Art. 6.3 del Decreto 77/2020 de la Generalitat de Cataluña y art. 18 del Decreto 79/2020 de la Comunidad de Madrid.

33 Ya en pruebas de imprenta este texto, se han seguido publicando nuevas normas autonómicas sobre el teletrabajo, entre las que destacan la Orden HAP/320/2021, de 31 de marzo, de Aragón y el Decreto 49/2021, de 1 de abril, de la Generalitat Valenciana. También parece inminente una regulación para la Administración del Estado. 